\title{
Evaluation of the mechanical resistance of rheophores of the means of initiation for explosive's materials, on the basis of the resistance to abrasion determined with the OPVA 10 specialized equipment
}

\author{
Cristian Radeanu ${ }^{{ }^{*}}$, Gabriel Vasilescu ${ }^{1}$, Claudia Miron ${ }^{1}$, Florin Vedinas ${ }^{2}$, and Ladislau \\ Radermacher $^{3}$ \\ ${ }^{1}$ National Institute for Research and Development in Mine Safety and Protection to Explosion, \\ Department of Safety of Explosion and Pyrotechnic Articles, G-ral V. Milea Street 32-34, Petrosani, \\ Romania \\ ${ }^{2}$ University of Petrosani, Doctoral School, Universitatii Street 22, Petrosani, Romania \\ ${ }^{3}$ University of Petrosani, Department of mining engineering, topography and construction, \\ Universitatii Street 22, Petrosani, Romania
}

\begin{abstract}
The scientific paper presents the synthesis of research results undertaken to develop the technical and methodological infrastructure for assessing the safety of means of initiating explosives, on the abrasion resistance of rheophores of electric detonators, in order to increase the safety of their use. The state-of-the-art OPVA 10 equipment is used to test the ability of rheophores insulation to withstand the abrasion forces that may occur during normal use. This equipment with a programmable automatic ensures the testing of the rheophores of the electric detonating staples to determine the abrasion resistance under the operating conditions provided by the harmonized European standard EN 13763-4 and the technical specification of the manufacturer, the operating temperature of this equipment being between $10 \div 30^{\circ} \mathrm{C}$ ensuring at the highest level the fulfillment of the technical requirements imposed by the European and international regulations in the field.
\end{abstract}

\section{Introduction}

Explosives for civilian use can be classified according to several criteria, one of which is essential to delimit them in terms of their role in carrying out the shooting operation. Thus, the explosives themselves can be distinguished (for rock dislocation) and the means of initiating explosives [1].

The initiating means are intended for the development of the energy that will detonate the explosives proper here having several types, namely: staples of various designs (pyrotechnic staples, electric detonating staples, non-electric detonating staples and

\footnotetext{
Corresponding author: cristian.radeanu@insemex.ro
} 
electronic detonating staples); detonating wicks and delay wicks used in conjunction with pyrotechnic staples; initiation explosives (busters). From a constructive point of view, the detonating staples listed above are equipped with electric rheophores or shock tubes with low explosive charge which are connected to the explosive suitable for their triggering (Figure 1) [2-4].

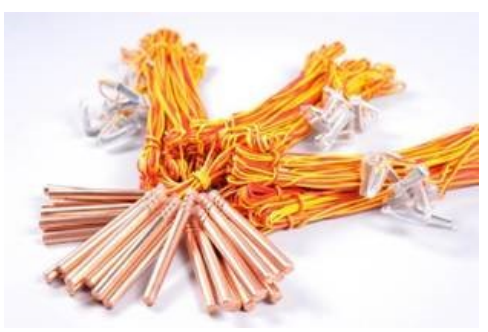

a. Electric detonator staples equipped with electric rheophores

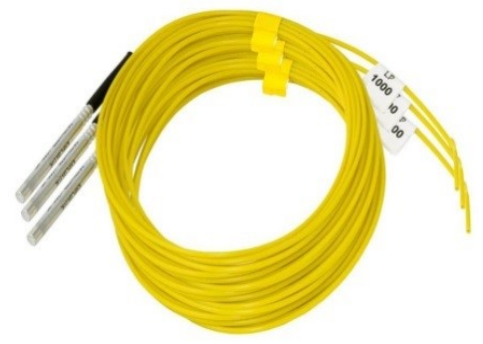

b. Non-electric detonating staples equipped with shock tubes

Fig. 1. Means of initiating explosives

Given that in many situations during use in the field during the loading and execution of the plugs of the shooting holes, there may be situations on the work front in which the rheophores and the shock tubes are subjected to mechanical stress under different conditions temperature $[5,6]$.

The insulation of the electric detonator staples and the plastic casing of the shock tube for non-electric detonators may be subjected to several forces, including abrasion forces, when pulled on rough surfaces and / or shear forces, when pulled over a sharp edge. In the event of partial or total damage to the rheophore or shock tube the detonator in question will not work, registering on the work front a partial or total failure, technical incident that requires additional work with costs and risks that are to be avoided $[7,8]$.

The topic addressed in the paper is of particular importance in terms of harmonizing the existing level of technical competence at national level with the international profile performance, regarding the observance of the security requirements specific to the means of initiation from the perspective of verification and ensuring keeping the integrity of the plastic casing related to the rheophores of electric detonators and shock tubes, following their testing under different temperature conditions at predetermined loads according to the applicable references.

\section{Determination of the safety parameter for abrasion sensitivity of rheophores and shock tubes}

Considering the requirements of Directive 2014/28 / EU transposed by GD 197/2016 respectively Technical Norms to Law 126/1995 the test and evaluation of abrasion sensitivity is an essential safety requirement that must be tested and evaluate.

The test method that is applied is a standardized one at European level applying the harmonized standard EN 13763-4: Determination of resistance to abrasion of leading wires and shock tubes. The test method that is applied is a standardized one at European level applying the harmonized standard EN 13763-4 Determination of the abrasion resistance of detonators of detonating caps and shock tubes. This reference describes the method for determining the abrasion resistance of plastics used as an insulating material for the rheophores of electrical detonating staples or used as a base material for the sheath of the shock tube. 
The principle of the test method is that the test specimens (thermally conditioned for at least 2 hours before the test) are subjected to abrasion on an abrasive surface, which moves at a certain speed, while applying the established load. For this purpose, for rheophores, the time required for the insulation to penetrate is determined, and for shock tubes, their operation is tested after immersion in water $[9,10]$.

To perform the test, a specialized test apparatus consisting of the following main components is required: (1) Joint, (2) Articulated arm, (3) Weight, (4) Pulleys, (5) Rod, (6) Weight, (7) Screw clamp for fixing the sample, (8) Clamp for fixing the sample, (9) Rotor (Figure 2).

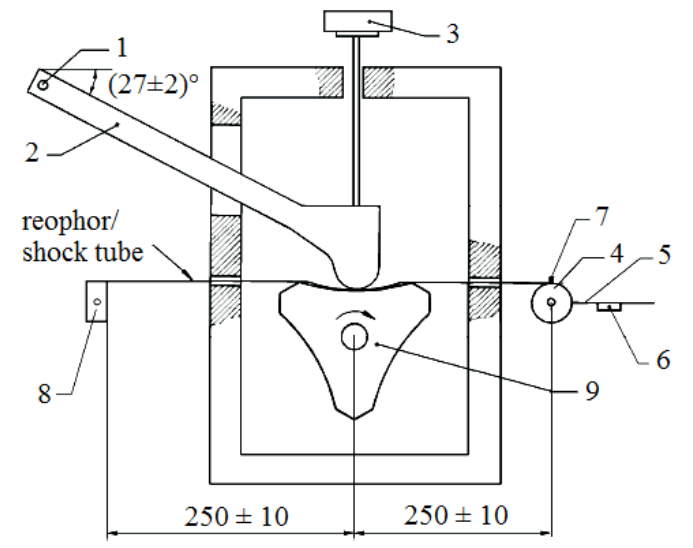

Fig. 2. Abrasion testing equipment

The components of this abrasion tester must meet a number of technical requirements: - The rotor (9) made of steel or brass, has a perimeter of $(453 \pm 2) \mathrm{mm}$, to which three abrasive strips with adhesive tape are attached. The rotor must rotate at a speed of $(9.96 \pm$ $0.18) \mathrm{rpm}$ so as to obtain an average peripheral speed of $(0,075 \pm 0,001) \mathrm{m} / \mathrm{s}$.

- The load to be applied to the specimen by means of the articulated arm (2) must be $(8,35$ $\pm 0,05) \mathrm{N}$.

- The pulley (4) has a diameter of $(70 \pm 1) \mathrm{mm}$ and allows a tensile load of $(8,1 \pm 0,5) \mathrm{N}$ to be applied to the test piece by means of a rod and a weight.

- Digital timer with relay output must be able to: can be adjusted to a predetermined duration, in the range (from 0 to 10$) \mathrm{s} \pm 0,1 \mathrm{~s}$; be switched on (triggered) when the articulated arm is raised by the sample; to automatically stop the rotor when the preset time has elapsed (required only for testing the shock tube); to turn off the rotor automatically when electrical contact is made between the rheophore and the abrasive belt or rotor (required only for rheophore testing) [10].

\subsection{Synthetic presentation of the test technical infrastructure}

For the determination of the abrasion resistance of the reophores of electric detonating staples and shock tubes according to the applicable reference EN 13763-4, a state-of-theart, high-performance equipment type OPVA 10 with the following main components was used: heating chamber operating panel (1), panel control unit with controller and display for operating the mechanical system (2), heating chamber (3), abrasion tester (4) (Figure 3) [11].

In the case of older equipment used for abrasion tests, the test pieces for thermal conditioning were placed in separate heating chambers. Those equipments were arranged in a location space that had to be serviced by test operators, and in which ensuring and 
maintaining temperature values at standard levels (after thermal conditioning) is difficult to achieve.

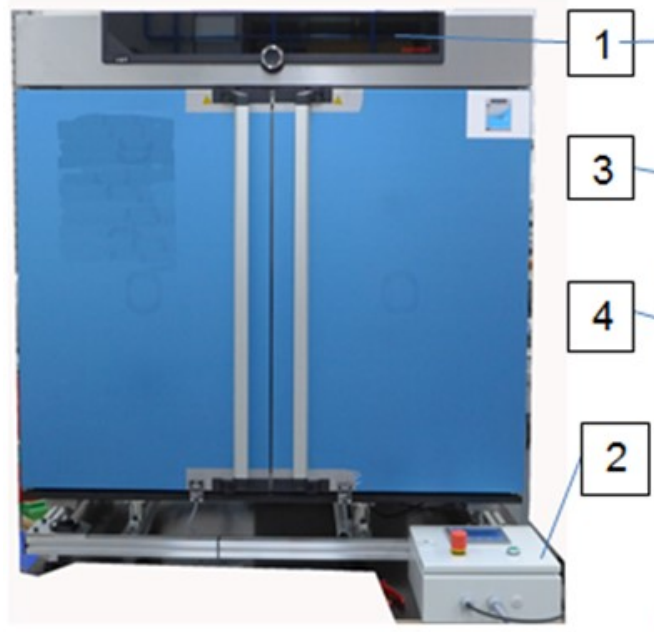

a. Front view

Fig. 3. Echipamentul specializat tip OPVA 10

The specialized equipment type OPVA 10 has the advantage of using the abrasion tester even in the heating chamber of the samples for testing.

\subsection{Carrying out tests using the specialized equipment type OPVA 10}

Before catching the shock wires / tubes, the load lever loads must be adjusted as well as the tensile forces of the required shock wires / tubes, according to the standard or by way of derogation from it, in accordance with the testing specifications. This may require modifications to the existing weights on the loading lever and the tensioning roller [10,11].

According to the working procedure PL-10 entitled "Working procedure for the use of OPVA 10 type equipment intended to determine the abrasion resistance of rheophores and shock tubes", to be proceed as follows:

- Lift the loading lever and secure it with the locking screw, pulling the locking screw and rotating it $90^{\circ}$.

- Insert the wire or shock tube into the ATG by clamping of left side part with a clip. In the case of a wire, the stripped part must pass to the left over the terminal block. The stripped wire must not be in contact with the terminal block or the clamp. The contact is made with a crocodile type clip.

- Guide the shock wire / tube over the rotor to the tension roller. Attach the insulated wire or shock tube on the tension roller with a clamp. The weights on the tensioner roller lever must be horizontal to the right after gripping.

- Place the loading lever on the wire on the rotor. To do this, lift the lever slightly, then release the locking screw by turning its head $90^{\circ}$. The shock wire or tube must be centered on the roller and centered on the fixing screws to obtain a precise positioning on the rotor.

- Close the heating cabinet door, so the abrasion tester is ready for the testing process.

- Start the control panel with the controller and start the PLC program. Heat the heating cabinet to the test temperature (caution: $\max .60^{\circ} \mathrm{C}$ ).

The technical facilities offered by the equipment allow its modern use by obtaining data and information displayed on the display of the PLC control unit (Figure 4a), the equipment also having the possibility to control the kinematic parameters of the rotation 
mechanism (Figure 4b) and how for setting the temperature of the heating chamber provided by the afferent panel (Figure 3).

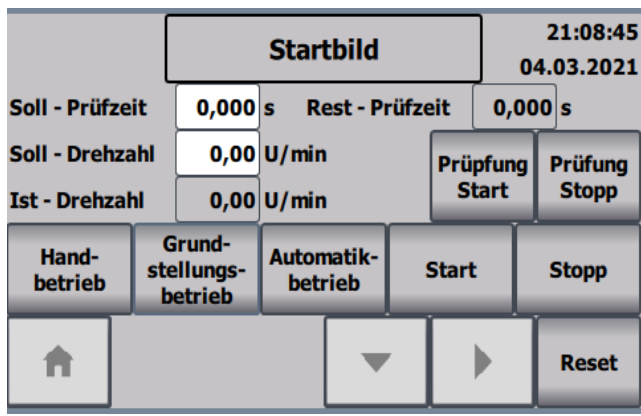

a. home screen

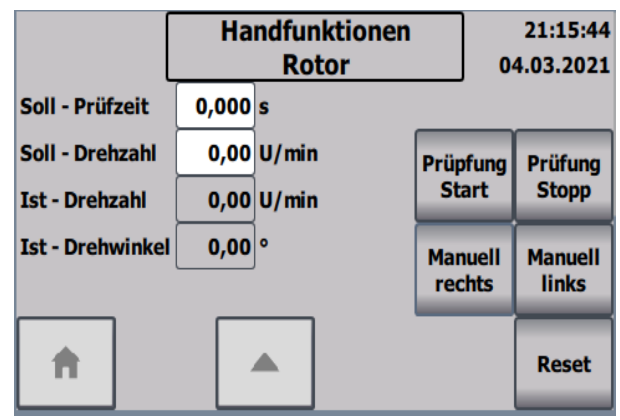

b. screen for rotor control

Fig. 4. PLC control unit main screen

After reaching the test temperature, the test procedure can be initiated using the operating system of the mechanical system [11].

For wire testing (rheophores) the rotation of the rotor is stopped after the wire insulation has been worn, or at the latest after the expiration of the maximum execution time set by the operating system of the mechanical system.

For testing of shock tubes the rotation of the rotor is stopped after the expiration of the test time set by the operating panel of the mechanical system.

\section{Calculation, expression and evaluation of results}

The results obtained from the tests for determining the abrasion resistance of the rheophores and the shock tubes respectively are recorded in the table in the Register of Primary Records (located at the test point) and subsequently must be recorded in the Test Report which must comply with EN ISO / IEC 17025 in which additionally the following information must be provided: for rheophores, the time elapsed until failure; for shock tubes, the number of shock tubes that did not initiate during the function test, and the number of shock tubes that did not propagate the full length initiation during the function test.

Results obtained from the determination of the abrasion resistance of the rheophores (subjected to thermal conditioning at $20^{\circ} \mathrm{C}$ ) related electric detonating staples type 30MMSED-Cu using specialized equipment type OPVA 10 are shown in Table 1.

Table 1. Results for the determination of the abrasion resistance of the rheophores of MMSED staples

\begin{tabular}{|c|c|c|c|c|c|}
\hline $\begin{array}{l}\text { Trial } \\
\text { no. }\end{array}$ & $\begin{array}{l}\text { Sample } \\
\text { length } \\
\text { (m) }\end{array}$ & $\begin{array}{l}\text { Load } \\
\text { applied } \\
\text { (N) }\end{array}$ & $\begin{array}{l}\text { Time elapsed } \\
\text { until failure } \\
\text { (s) }\end{array}$ & $\begin{array}{c}\text { Temperature } \\
\left({ }^{\circ} \mathrm{C}\right)\end{array}$ & Remarks \\
\hline 1. & 0.7 & 4.0 & 8.54 & 20 & \multirow{10}{*}{$\begin{array}{c}\text { Average time } \\
\text { elapsed until failure } \\
\text { is } 9.63 \mathrm{~s}\end{array}$} \\
\hline 2. & 0.7 & 4.0 & 9.59 & 20 & \\
\hline 3. & 0.7 & 4.0 & 10.53 & 20 & \\
\hline 4. & 0.7 & 4.0 & 9.55 & 20 & \\
\hline 5. & 0.7 & 4.0 & 9.73 & 20 & \\
\hline 6. & 0.7 & 4.0 & 10.55 & 20 & \\
\hline 7. & 0.7 & 4.0 & 9.53 & 20 & \\
\hline 8. & 0.7 & 4.0 & 10.55 & 20 & \\
\hline 9. & 0.7 & 4.0 & 9.50 & 20 & \\
\hline 10. & 0.7 & 4.0 & 8.23 & 20 & \\
\hline
\end{tabular}


Further, to exemplify the trend of result indicators, 10 tests were performed to determine the abrasion resistance of the rheophores of MMSED type electrical staples, at different conditioning temperatures, and the results were recorded in Table 2.

Table 2. Determination of abrasion resistance of rheophores for different temperatures

\begin{tabular}{|l|c|c|c|c|c|}
\hline $\begin{array}{c}\text { No. } \\
\text { crt. }\end{array}$ & $\begin{array}{c}\text { Samples } \\
\text { length } \\
(\mathrm{m})\end{array}$ & $\begin{array}{c}\text { Load } \\
\text { applied } \\
(\mathrm{N})\end{array}$ & $\begin{array}{c}\text { Average time } \\
\text { elapsed until failure } \\
(\mathrm{s})\end{array}$ & $\begin{array}{c}\text { Temperature } \\
\left({ }^{\circ} \mathrm{C}\right)\end{array}$ & \multirow{2}{*}{ Remarks } \\
\hline 1. & 0.7 & 4.0 & 9.63 & 20 & \multirow{2}{*}{ Average time $>6 \mathrm{~s}$} \\
\hline 2. & 0.7 & 4.0 & 9.05 & 30 & \\
\hline 3. & 0.7 & 4.0 & 8.25 & 40 & \\
\hline 4. & 0.7 & 4.0 & 7.05 & 50 & \multirow{2}{*}{ s. } \\
\cline { 1 - 4 } 5. & 0.7 & 4.0 & 6.25 & 60 & \\
\hline
\end{tabular}

Results obtained after the determination of the abrasion resistance of the shock tubes (thermally conditioned at $20^{\circ} \mathrm{C}$ ) related to the pyrotechnic staples type RIONEL MS, using the specialized equipment type OPVA 10 are shown in Table 3.

Table 3. Results for the determination of the abrasion resistance of the shock tubes related to RIONEL pyrotechnic staples

\begin{tabular}{|c|c|c|c|c|c|c|c|}
\hline $\begin{array}{c}\text { Trial } \\
\text { no. }\end{array}$ & $\begin{array}{l}\text { Length } \\
\text { of shock } \\
\text { tube } \\
(\mathrm{mm})\end{array}$ & $\begin{array}{l}\text { Conditioning } \\
\text { Chamber } \\
\text { Temperature } \\
\left({ }^{\circ} \mathrm{C}\right)\end{array}$ & $\begin{array}{l}\text { Load } \\
\text { applied } \\
\text { (N) }\end{array}$ & $\begin{array}{l}\text { Time } \\
\text { elapsed } \\
\text { until } \\
\text { failure } \\
\text { (s) } \\
\end{array}$ & $\begin{array}{c}\text { Shock } \\
\text { Tube } \\
\text { Initiate } \\
\mathrm{Y} / \mathrm{N}\end{array}$ & $\begin{array}{l}\text { Shock tube } \\
\text { propagate entire } \\
\text { length during } \\
\text { functioning } \\
\mathrm{Y} / \mathrm{N} \\
\end{array}$ & Remarks \\
\hline 1 & 3,000 & 20 & 12.2 & 6.52 & $\mathrm{Y}$ & $\mathrm{Y}$ & \multirow{10}{*}{$\begin{array}{l}\text { Average } \\
\text { time } \\
\text { elapsed } \\
\text { until failure } \\
\text { is } 6.47 \mathrm{~s}\end{array}$} \\
\hline 2 & 3,000 & 20 & 12.2 & 6.55 & $\mathrm{Y}$ & $\mathrm{Y}$ & \\
\hline 3 & 3,000 & 20 & 12.2 & 6.50 & $\mathrm{Y}$ & $\mathrm{Y}$ & \\
\hline 4 & 3,000 & 20 & 12.2 & 6.48 & $\mathrm{Y}$ & $\mathrm{Y}$ & \\
\hline 5 & 3,000 & 20 & 12.2 & 6.45 & $\mathrm{Y}$ & $\mathrm{Y}$ & \\
\hline 6 & 3,000 & 20 & 12.2 & 6.45 & $\mathrm{Y}$ & $\mathrm{Y}$ & \\
\hline 7 & 3,000 & 20 & 12.2 & 6.45 & $\mathrm{Y}$ & $\mathrm{Y}$ & \\
\hline 8 & 3,000 & 20 & 12.2 & 6.45 & $\mathrm{Y}$ & $\mathrm{Y}$ & \\
\hline 9 & 3,000 & 20 & 12.2 & 6.51 & $\mathrm{Y}$ & $\mathrm{Y}$ & \\
\hline 10 & 3,000 & 20 & 12.2 & 6.50 & $\mathrm{Y}$ & $\mathrm{Y}$ & \\
\hline
\end{tabular}

In order to exemplify the trend of result indicators, 10 samples were tested to determine the abrasion resistance of the shock tubes related to RIONEL type non-electric staples at different conditioning temperatures and the results were recorded in Table 4.

Table 4. Determination of abrasion resistance of shock tubes for different temperatures

\begin{tabular}{|c|c|c|c|c|c|c|c|}
\hline $\begin{array}{l}\text { No. } \\
\text { crt. }\end{array}$ & $\begin{array}{c}\text { Length } \\
\text { of shock } \\
\text { tube } \\
(\mathrm{mm})\end{array}$ & $\begin{array}{c}\text { Conditioning } \\
\text { Chamber } \\
\text { Temperature } \\
\left({ }^{\circ} \mathrm{C}\right)\end{array}$ & $\begin{array}{l}\text { Load } \\
\text { applied } \\
\text { (N) }\end{array}$ & \begin{tabular}{|c|} 
Average \\
time elapsed \\
until failure \\
(s)
\end{tabular} & $\begin{array}{c}\text { Shock } \\
\text { Tube } \\
\text { Initiate } \\
\mathrm{Y} / \mathrm{N}\end{array}$ & $\begin{array}{c}\text { Shock tube } \\
\text { propagate entire } \\
\text { length during } \\
\text { functioning } \\
\text { Y/N }\end{array}$ & Remarks \\
\hline 1 & 3,000 & 20 & 12.2 & 6.47 & $\mathrm{Y}$ & $\mathrm{Y}$ & \multirow{5}{*}{$\begin{array}{c}\text { Average } \\
\text { time }>4.5 \mathrm{~s}\end{array}$} \\
\hline 2 & 3,000 & 30 & 12.2 & 6.15 & $\mathrm{Y}$ & $\mathrm{Y}$ & \\
\hline 3 & 3,000 & 40 & 12.2 & 5.65 & $\mathrm{Y}$ & $\mathrm{Y}$ & \\
\hline 4 & 3,000 & 50 & 12.2 & 5.28 & $\mathrm{Y}$ & $\mathrm{Y}$ & \\
\hline 5 & 3,000 & 60 & 12.2 & 5.02 & $\mathrm{Y}$ & $\mathrm{Y}$ & \\
\hline
\end{tabular}

Considering the results of the tests regarding the determination of the abrasion resistance of the rheophores of the MMSED type electric detonating staples and of the shock tubes related to the RIONEL non-electric staples it can be appreciated that in both 
situations there is a similar tendency of variation of the average time elapsed until failure, in the sense that with the increase of the test temperature (which highlights the dynamics of the test mode to ensure the extreme temperature condition with the value of $60^{\circ} \mathrm{C}$ located at the maximum range, according to the technical specification of the product) this parameter is manifested by a decrease in value approaching the maximum permissible lower limits ( $6 \mathrm{~s}$ for rheophores of electrical detonators and $4.5 \mathrm{~s}$ for shock tubes), which means a decrease in performance on meeting the safety requirement.

\section{Conclusions}

This acquisition and the tests performed with the OPVA 10 equipment allow the exact testing and evaluation according to the EN 13763-4 standard of this parameter under the conditions specified with ensuring the traceability of the results and the possibilities of intercomparison with other specialized laboratories that have identical or similar with the equipment from the endowment of the Laboratory of Explosive Materials and Pyrotechnic Articles of INSEMEX.

The use of high-performance OPVA equipment offers the advantage of performing all the operations provided in the test procedure inside the equipment ensuring the testing of specimens at predetermined temperatures, provided in the product data sheets as opposed to specialized equipment for the same type of test, which is willing only in a location space and have to be served by test operators, and in which ensuring and maintaining temperature values at standard levels is difficult to achieve.

The results of the tests for abrasion resistance of the electric detonator reophores and shock tubes show that the safety requirement of this parameter has been met by framing the average and minimum values of the test time at the point of failure, within the limits of acceptability as follows: for rheophores of electrical detonating staples the average time greater than $6.0 \mathrm{~s}$ and minimum time greater than $5.1 \mathrm{~s}$; for shock tubes the average time greater than $4.5 \mathrm{~s}$ and the minimum time greater than $3.8 \mathrm{~s}$.

Acknowledgements: This paper was developed within the Project PN-19 2102 02, Program developed with the support of the National Authority for Scientific Research and Innovation ANCSI.

\section{References}

1. R. Holmberg, Explosives and Blasting Technique (Swets \& Zeitlinger B.V., Lisse, 2003)

2. D. Rus, GD. Vasilescu, E. Gheorghiosu, C. Jitea, EEMJ, 16, 1361, (2017)

3. D. Rus, E. Ghicioi, R. Laszlo, C. Rădeanu, A Kovacs, G. Vasilescu, Quality-Access to Success, 20, 37-42, (2019)

4. E. Gheorghiosu, E. Ghicioi, A. Kovacs, G. Vasilescu, D. Rus, Environmental Engineering and Management Journal, 16, 1283, (2017)

5. E. Gheorghiosu, A. Kovacs, G. Vasilescu, S. Neacsu, C. Jitea, S. Bordos, SGEM 2017, The conformity of delayed ignition means as key factor on a safe blasting in quarries, (Albena, Bulgaria, 2017)

6. G. Vasilescu, E. Ghicioi, A. Kovacs, D. Rus, E. Gheorghiosu, C. Jitea, S. Bordos, BALKANMINE 2015, "Assessment of electrical detonators from point of view of the delay precisions, regardly the harmonized european standard, (Petrosani, Romania, 2015)

7. D. Rus, GD. Vasilescu, E. Gheorghiosu, C. Jitea, Quality-Access to Success, 18, 41, (2017)

8. D. Rus, A. Kovacs, E. Ghicioi, GD. Vasilescu, Annals of the University of Petroșani, Electrical Engieering, 15, 19, (2013) 
9. Directive 2014/28/UE of the European Parliament and of the Council of 26 February 2014 on the harmonisation of the laws of the Member States relating to the making available on the market of explosives for civil uses

10. EN 13631-4:2003, Explosives for civil uses, Detonators and relays - Determination of resistance to abrasion of leading wires and shock tubes (2003)

11. User manual OPVA 10, Fr. Sobbe GmH /www.sobbe-zuender.de 